\title{
PENGARUH PERBEDAAN KARAKTERISTIK BRAND AMBASSADOR TERHADAP KEPUTUSAN PEMBELIAN KONSUMEN RUANGGURU
}

\author{
Andrean Fredy Iswanto \\ Fakultas Ekonomi, Universitas Negeri Surabaya \\ andreaniswanto16080574107@mhs.unesa.ac.id \\ Sanaji Sanaji \\ Fakultas Ekonomi, Universitas Negeri Surabaya \\ sanaji@unesa.ac.id
}

\begin{abstract}
The emergence of Ruangguru, an online-based tutoring application in 2014, has been very intriguing because it defeated several competitors, including Zenius.net, a pioneer of online-based tutoring applications in Indonesia. Ruangguru uses several Brand ambassadors and Celebrity Endorsers to support their brands with differences in professional and characteristic fields. This study examines whether there are differences in the influence of several brand ambassadors from Ruangguru with different characteristics/professions towards purchasing decisions. This study uses 200 samples with non-probability sampling techniques, and the method used is judgmental sampling. The data collection method uses questionnaires online. The data analysis technique used in this study is Regression and ANOVA. The result is that the differences in Ruangguru brand ambassadors' average influence on consumer and professional purchasing decisions increase significant differences, "Singer" and "Athlete". The Brand ambassador influences the Purchasing Decision, with 13\% being the Brand Ambassador's influence and the remaining $87 \%$ is influenced by other factors not examined.
\end{abstract}

Keyword: anova; brand ambassador; celebrity endorser; purchase decision; ruangguru.

\section{PENDAHULUAN}

Berdasarkan survey yang dilakukan oleh APJII (Asosiasi Penyelenggara Jasa Internet Indonesia) pada tahun 2018 memperlihatkan bahwa 171,17 juta dari total jumlah penduduk Indonesia sebesar 264,16 juta orang sebanyak 64,8\% merupakan pengguna internet. Survei yang dilakukan oleh APJII menunjukkan bahwa alasan penggunaan internet untuk mencari data terkait pendidikan berada di urutan ke-empat yakni dengan jumlah sebesar 9,6\%. Pelajar di Indonesia jadi salah satu pengguna teknologi tertinggi di dunia, penelitian yang dilakukan oleh organisasi pendidikan terkemuka Cambridge International, menemukan pelajar Indonesia menduduki peringkat kedua tertinggi di dunia dalam penggunaan computer desktop (54\%) (bbc.com, 2018). Berdasarkan laporan terbaru We Are Social, yang dikutip dalam detik.com pada tahun 2020 disebutkan bahwa ada 175,4 juta pengguna internet di Indonesia. Dibandingkan tahun sebelumnya, ada kenaikan $17 \%$ atau 25 juta pengguna internet di negeri ini, dari total populasi Indonesia yang berjumlah 272,1 juta jiwa, maka itu artinya 64\% setengah penduduk RI telah merasakan akses ke dunia maya. Dengan berkembangnya penggunaan internet di Indonesia ini, secara global memengaruhi segala aspek termasuk di dalamnya ialah dunia pendidikan. Perkembangan tersebut dapat memberikan cara-cara baru dalam kegiatan belajar seperti interaksi guru dan murid secara online. Dengan begitu perkembangan dunia pendidikan non-formal atau biasa disebut dengan Bimbel (Bimbingan Belajar) kini juga bisa kita temui secara online (B. Uno dan Lamatenggo, 2017). Perkembangan penggunaan internet di Indonesia juga memicu pertumbuhan bimbingan belajar online yang sangat mudah di akses oleh para pelajar dengan gadget yang dimilikinya. Menurut Katadata.co.id (2020), beberapa platform aplikasi belajar online yang terdapat di Indonesia adalah Ruangguru (15 Juta Pelajar), Zenius.net (12 Juta Pelajar), Quipper (6 Juta Pelajar), dan Rumah Belajar (1 Juta Pelajar).

Dalam upaya ikut serta mencerdaskan anak bangsa peran bimbingan belajar sangatlah penting untuk mencakup perkembangan ilmu pengetahuan di Indonesia. Banyak siswa yang merasa kurang mendapatkan pelajaran di sekolah maka dari itu mengikuti bimbingan belajar menjadi salah satu solusi untuk menutup segala kekurangan pembelajaran saat di sekolah. Jika kita lihat dari kenyataan 
lembaga bimbingan belajar akan semakin ramai terutama dari siswa tingkat akhir dan menjelang ujian, akan tetapi dari beberapa tahun terakhir ada fenomena baru ketika mulai munculnya lembaga bimbingan belajar berbasis online seperti Ruangguru, Zenius, Rumah Belajar, Quipper yang mulai menunjukkan eksistensinya dan mereka pun bersaing dengan bimbingan belajar konvensional yang sudah memiliki nama besar seperti Ganesha Operation dan Primagama. Efek dari kedua persaingan inipun yaitu mulai banyak kegiatan promosi serta testimoni kepada masyarakat, salah satunya Ruangguru yang bekerja sama dengan aktor muda Iqbal Ramadhan, aktor yang pernah membintangi Film yang sempat fenomenal beberapa waktu lalu yaitu Dilan 1990 ini dijadikan salah satu brand ambassador mereka (Kompasiana.com, 2020). Kemampuan perusahaan dalam mengkomunikasikan produk ke konsumen sangat penting. Hal ini dilakukan untuk menarik konsumen. Promosi adalah sarana di mana perusahaan berusaha menginformasikan, membujuk dan mengingatkan konsumen secara langsung maupun tidak langsung tentang produk dan merek yang dijual (Kotler dan Keller, 2016:219). Menurut Sumarwan (2014:312) kelompok acuan adalah yang paling sering di pakai perusahaan untuk mengiklankan atau mempromosikan berbagai produk dan jasa. Di dalam kelompok acuan, para selebriti adalah salah satu cara yang sering dipakai dan memiliki pengaruh yang kuat kepada konsumen dalam keputusan pembelian produk dan jasa, serta pemilihan merek.

Menurut Kotler dan Keller (2016:166) proses psikologis dasar memainkan peran penting dalam memahami bagaimana konsumen benar-benar membuat sebuah keputusan pembelian. Sedangkan menurut Schiffman dan Kanuk (2008:485), keputusan pembelian adalah seleksi terhadap dua pilihan alternatif atau lebih. Pengambilan keputusan yang dilakukan oleh konsumen dalam melakukan suatu pembelian produk barang maupun jasa dapat diawali dengan kesadaran atas kebutuhan dan keinginan. Wang et. al (2016) menyatakan brand ambassador atau celebrity endorsement akan membantu menciptakan hubungan emosional yang lebih kuat antara merek dengan konsumen sehingga secara tidak langsung akan membangun citra dampak produk pada keputusan pembelian.

Menurut Lea-Greenwood (2012:77), seorang brand ambassador seharusnya memiliki sebuah kecocokan (kesesuaian) dengan merek agar bisa mendukung sebuah merek yang terkait berdasarkan profesi mereka. Namun salah satu brand ambassador Ruangguru yaitu Justin atau biasa disebut sebagai Jess No Limit merupakan seorang Professional Gamer yang memiliki konten gaming pada semua platform media sosial yang ia gunakan. Sedangkan Kurniawan (2017) menjelaskan beberapa dampak akibat tingginya intensitas bermain game online menjadi tidak memiliki skala prioritas dalam menjalani aktivitas sehari-hari serta menyebabkan remaja menjadi malas belajar. Hal serupa dikemukakan oleh Putra et al. (2014), jika game online dapat menyebabkan kecanduan, hal ini dapat berakibat kurangnya waktu istirahat anak dan kemudian dapat memengaruhi kegiatan sekolahnya. Dengan begitu dapat diartikan bahwa profesi seorang Justin atau Jess No Limit sebagai seorang Professional Gamer ini sangat bertolak belakang dengan merek di mana Ruangguru merupakan sebuah penyedia jasa bimbel online.

Pada penelitian Putra et al. (2014) brand ambassador berpengaruh terhadap variabel keputusan pembelian. Hafilah et al. (2019) menjelaskan bahwa variabel yang memiliki pengaruh besar terhadap keputusan pembelian adalah kualitas produk. Sementara itu, variabel yang memiliki dampak rendah pada keputusan pembelian adalah brand ambassador. Brand ambassador memiliki koefisien negatif yang menunjukkan bahwa tidak terlalu berpengaruh dalam keputusan pembelian. Wang et al. (2016) menunjukkan bahwa brand ambassador itu sendiri kurang efektif dalam memengaruhi keputusan pembelian konsumen. Pada penelitian Samosir et.al. (2016) berdasarkan koefisien determinasi, besarnya pengaruh Dewi Sandra sebagai brand ambassador kosmetik Wardah terhadap keputusan pembelian tidak sepenuhnya dipengaruhi oleh variabel brand ambassador, namun sebagian besar dipengaruhi oleh variabel lain yang tidak diteliti. Penggunaan Dewi Sandra sebagai brand ambassador kosmetik wardah tidak berpengaruh besar dalam putusan konsumen dalam membeli. Menurut Yusiana dan Maulida (2015), penggunaan Gita Gutawa sebagai brand ambassador dapat disetujui oleh konsumen sebagai salah satu alasan untuk membeli produk Pond's. Prawira et.al. (2012) menjelaskan bahwa penggunaan brand ambassador tidak sepenuhnya mempunyai hubungan terhadap tahapan keputusan pembelian, ada faktor-faktor lain yang menyebabkan tahapan keputusan 
Iswanto \& Sanaji. Pengaruh Perbedaan Karakteristik Brand Ambasador terhadap Keputusan Pembelian Konsumen Ruangguru

pembelian konsumen. Berdasarkan hasil penelitian terdahulu, menunjukkan bahwa terdapat kesenjangan hasil penelitian pengaruh penggunaan brand ambassador terhadap keputusan pembelian.

Penelitian ini bertujuan untuk mengetahui apakah terdapat perbedaan pengaruh rata-rata dari brand ambassador Ruangguru terhadap keputusan pembelian konsumen, dalam penelitian Prawira et. al (2012) menyebutkan bahwa karakteristik seorang brand ambassador harus dapat memberikan pengaruh keputusan pembelian dan dapat mengubah sikap dari seorang. Kemudian dalam penelitian Apejoye (2013) juga menyebutkan bahwa setiap endorser memiliki power, dan setiap jumlah power ini dapat menentukan sejauh mana perilaku konsumen dipengaruhi. Pada penggunaan brand ambassador Ruangguru ini lebih dari 1 orang dan mereka juga memiliki profesi/karakteristik yang berbeda-beda yakni, Aktor, Content Creator, Penyanyi, Atlet, dan Gamer Professional sehingga dengan begitu beberapa brand ambassador ini juga pastinya akan memberikan pengaruh yang berbeda kepada konsumen Ruangguru. Penelitian ini juga untuk mengetahui seberapa besar pengaruh yang diberikan brand ambassador terhadap keputusan pembelian konsumen pada Ruangguru.

\section{KAJIAN PUSTAKA DAN PENGEMBANGAN HIPOTESIS}

\section{Brand ambassador/Celebrity Endorser}

Wang et al. (2016) menjelaskan bahwa brand ambassador atau celebrity endorser merupakan seorang pendukung merek yang bertugas untuk membantu menciptakan hubungan emosional yang kuat antara perusahaan dengan para konsumen dan secara tidak langsung penggunaan brand ambassador atau celebrity endorser ini akan membangun citra produk. Brand ambassador nantinya akan menjelaskan proses terkait dengan penggunaan produk dan juga manfaat dari produk tersebut dan mengapa konsumen harus memilih produk tersebut. Goutam (2013) menjelaskan bahwa brand ambassador merupakan seorang duta yang menjadi perwakilan juru bicara dari sebuah merek atau perusahaan. Sedangkan definisi celebrity endorser menurut Shimp, (2007:302), celebrity endorser merupakan konsep untuk memfungsikan seorang artis, entertainer, atlet, dan para public figure yang banyak diketahui oleh banyak lapisan masyarakat.

Prawira et al. (2012) mengemukakan bahwa terdapat beberapa indicator brand ambassador yang dikenal dengan VisCAP: (1) Visibility (kepopuleran), ialah popularitas yang melekat pada brand ambassador yang mewakili produk tersebut. (2) Credibility (kredibilitas), keahlian dan kepercayaan yang diberikan oleh brand ambassador. (3) Attraction (daya tarik), yakni meliputi daya tarik fisik, serta sekumpulan nilai seperti kemampuan intelektual, karakter gaya hidup yang dapat diterima khalayak dari seorang brand ambassador. (4) Power (kekuatan), tingkat kekuatan seorang selebriti dalam membujuk para konsumen dalam membeli/memakai produk yang diiklankan atau menjadi seorang brand ambassador dari sebuah merek maupun perusahaan.

\section{Keputusan Pembelian}

Menurut Kotler dan Amstrong (2014:226) keputusan pembelian merupakan tahap dalam proses pengambilan keputusan pembelian dimana konsumen benar-benar membeli. Pengambilan keputusan merupakan suatu kegiatan individu yang secara langsung terlibat dalam mendapatkan dan mempergunakan barang yang ditawarkan. Sedangkan menurut Schiffman dan Kanuk (2008:289), keputusan pembelian adalah suatu keputusan seseorang dimana dia memilih salah satu dari beberapa alternatif pilihan yang ada. Berdasarkan pendapat tersebut, dapat disimpulkan bahwa keputusan pembelian adalah suatu tindakan yang dilakukan oleh konsumen untuk memenuhi akan kebutuhannya. Kemudian terdapat 5 pengukuran atas keputusan pembelian menurut Makgosa et.al. (2007) yaitu: (1) pilihan produk, (2) mengapa membeli, (3) kapan membeli, (4) dimana membeli, (5) seberapa sering membeli. Dalam penelitian ini indikator keputusan pembelian yang digunakan adalah indikator menurut Kotler (2007:222) ada empat indikator keputusan pembelian, yaitu: (1) kemantapan pada sebuah produk, (2) kebiasaan dalam membeli produk, (3) memberikan rekomendasi kepada orang lain, (4) melakukan pembelian ulang. 


\section{Perbedaan Pengaruh Brand ambassador Berdasarkan Profesi/Karakteristik}

Selebriti bisa memiliki pengaruh yang kuat kepada konsumen dalam pembelian produk dan jasa, serta pemilihan pada sebuah merek. Pengaruh tersebut bisa berbentuk adanya sebuah keinginan seorang konsumen untuk mengasosiasikan dirinya dengan para selebriti. Sumarwan (2014:312). Prawira et.al. (2012) menyebutkan bahwa karakteristik brand ambassador harus dapat menimbulkan keputusan pembelian, sehingga dapat mengubah sikap dari seorang konsumen. Selebriti hadir diberbagai bidang, termasuk hiburan, olahraga, sains, politik, dan telah menjadi pusat bagi para konsumen (Lunardo dan Roux, 2015). Menurut Rice et.al. (2012), masih sedikit penelitian yang meneliti tentang penggunaan beberapa selebriti untuk mengiklankan satu merek atau perusahaan (multiple celebrity endorsers) merupakan sebuah strategi yang efektif.

Kok dan You (2013) menyatakan bahwa, studi-studi tentang celebrity endorsement menyangkut konstruksi efek sumber pada karakteristik sumber yang berbeda. Karakteristik sumber ini memengaruhi komunikasi persuasif yang disampaikan kepada target audiens. Secara karakteristik daya tarik sumber dapat didefinisikan sebagai sifat yang menarik dari para artis atau selebriti seperti fisik, kepribadian, keakraban dan kesukaan terhadap konsumen. Sehingga terdapat beberapa perbedaan karakteristik maupun profesi dengan bidang yang berbeda-beda pada brand ambassador Ruangguru ini jelas akan memengaruhi target audiens dan memberikan pengaruh yang berbeda. Apejoye (2013) menjelaskan bahwa setiap endorser memiliki power, power disini adalah kekuatan dari endorser untuk memberikan pengaruh kepada orang lain dan setiap jumlah power ini dapat menentukan sejauh mana perilaku orang lain dipengaruhi. Penggunaan pendukung merek pada ruangguru ini terdapat banyak endorser, dan setiap endorser pastinya memiliki power yang berbedabeda, sehingga dapat memberikan pengaruh perilaku konsumen dari ruangguru yang berbeda pula.

H1 : Terdapat perbedaan rata-rata tingkat pembelian berdasarkan perbedaan pengaruh brand ambasador Ruangguru.

Putra et.al. (2014), menjelaskan bahwa brand ambassador berpengaruh signifikan terhadap keputusan pembelian. Akan tetapi menurut Hafilah et.al. (2019) brand ambassador memiliki arah korelasi negatif yang signifikan terhadap keputusan pembelian. Wang et.al. (2019) menunjukkan bahwa brand ambassador kurang efektif dalam memengaruhi keputusan pembelian konsumen. Kemudian menurut Yusiana dan Maulida (2015), pengaruh Gita Gutawa sebagai brand ambassador Pond's dapat disetujui oleh konsumen sebagai salah satu alasan untuk membeli produk Pond's. Kemudian dalam penelitian Samosir et.al. (2016) Dewi Sandra sebagai brand ambassador kosmetik Wardah berpengaruh terhadap keputusan pembelian konsumen.

$\mathrm{H} 2$ : Brand ambassador berpengaruh positif terhadap keputusan pembelian konsumen pada Ruangguru.

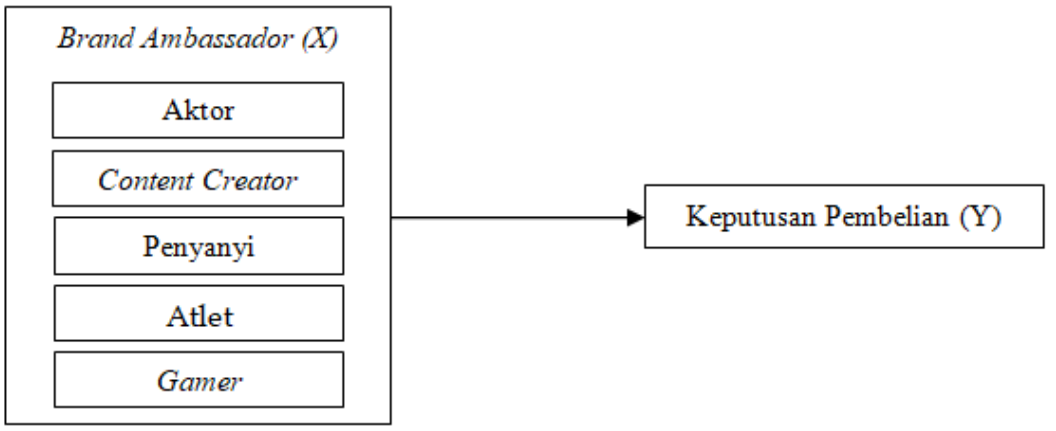

Sumber: diolah penulis, 2020

Gambar 1. MODEL PENELITIAN 
Iswanto \& Sanaji. Pengaruh Perbedaan Karakteristik Brand Ambasador terhadap Keputusan Pembelian Konsumen Ruangguru

\section{METODE PENELITIAN}

Populasi dalam penelitian ini adalah pelajar yang sedang duduk di bangku sekolah dan mengetahui tentang bimbingan belajar berbasis online Ruangguru beserta dengan Brand ambassador-nya dengan karakteristik usia 11 - >19 tahun. Teknik sampling yang digunakan dalam penelitian ini adalah nonprobability sampling dengan metode judgemental sampling. Terdapat 220 responden yang diperoleh dalam pengambilan data dan 220 responden disini mencakup semua dari karakteristik atau profesi brand ambassador. Dimensi dan indikator yang digunakan untuk mengukur variabel brand ambassador dan keputusan pembelian yang digunakan oleh beberapa peneliti sebelumnya dan telah disesuaikan dengan obyek penelitian (tabel 1). Skala pengukuran pada penelitian ini adalah skala likert, dimana responden diminta untuk menandai nilai persetujuan atau ketidaksetujuan mengenai objek penelitian. Pengumpulan data dilakukan dengan menyebarkan kuesioner secara online melalui Instagram, Whatsapp dan Youtube ditujukkan kepada seluruh pelajar di Indonesia yang menggunakan layanan bimbingan belajar secara online dari Ruangguru. Teknik analisis yang digunakan dalam penelitian ini menggunakan Regresi dan ANOVA.

Tabel 1

DIMENSI DAN INDIKATOR VARIABEL

\begin{tabular}{|c|c|c|c|}
\hline Variabel & Peneliti & Dimensi & Indikator \\
\hline \multirow[t]{4}{*}{$\begin{array}{l}\text { Brand } \\
\text { ambassador }\end{array}$} & $\begin{array}{l}\text { Sagia (2018); } \\
\text { Maharani (2015) }\end{array}$ & Popularitas(Visibility) & $\begin{array}{l}\text { 1. Popularitas di mata masyarakat } \\
\text { 2. Dikagumi masyarakat } \\
\text { 3. Sering muncul di media sosial }\end{array}$ \\
\hline & $\begin{array}{ll}\text { Paticia } & (2014) ; \\
\text { Royan } & (2005) ; \\
\text { Maharani } & (2015) ; \\
\text { Sagia (2018) }\end{array}$ & $\begin{array}{l}\text { Kredibilitas } \\
\text { (Credibility) }\end{array}$ & $\begin{array}{l}\text { 1. Memiliki citra yang baik } \\
\text { 2. Menjadi contoh yang baik untuk masyarakat } \\
\text { 3. Orang yang jujur } \\
\text { 4. Dapat diandalkan untuk menjadi seorang } \\
\text { brand ambassador } \\
\text { 5. Pandai dalam mempromosikan produk } \\
\text { 6. Produk yang didukung dapat dipercaya }\end{array}$ \\
\hline & $\begin{array}{ll}\text { Royan } & (2005) ; \\
\text { Sagia } \quad(2018) ; \\
\text { Maharani (2015); } \\
\text { Paticia (2014) }\end{array}$ & Daya tarik (Attraction) & $\begin{array}{l}\text { 1. Pribadi yang sopan dan santun } \\
\text { 2. Daya tarik yang kuat } \\
\text { 3. Kepribadian yang menarik }\end{array}$ \\
\hline & $\begin{array}{ll}\text { Sagia } & (2018) ; \\
\text { Royan } & (2005) ; \\
\text { Maharani,(2015) }\end{array}$ & Kekuatan (Power) & $\begin{array}{l}\text { 1. Memiliki kelebihan sebagai brand } \\
\text { ambassador } \\
\text { 2. Dapat mendukung merek yang didukung } \\
\text { 3. Meningkatkan citra merek }\end{array}$ \\
\hline \multirow[t]{2}{*}{$\begin{array}{l}\text { Keputusan } \\
\text { Pembelian }\end{array}$} & & $\begin{array}{l}\text { 1. Kemantapan pada } \\
\text { sebuah produk }\end{array}$ & $\begin{array}{l}\text { 1. Ruangguru bimbel terbaik } \\
\text { 2. Ruangguru pilihan prioritas saya } \\
\text { 3. Adanya brand ambassador menjadikan } \\
\text { Ruangguru alternatif terbaik }\end{array}$ \\
\hline & Kotler (200/:222) & $\begin{array}{l}\text { 2. Memberikan } \\
\text { rekomendasi kepada } \\
\text { orang lain } \\
\text { 3. Melakukan } \\
\text { pembelian ulang }\end{array}$ & $\begin{array}{l}\text { Merekomendasikan Ruangguru kepada orang } \\
\text { lain }\end{array}$ \\
\hline
\end{tabular}

Sumber: beberapa artikel (diolah peneliti) 


\section{HASIL DAN PEMBAHASAN}

\section{Uji Validitas dan Reliabilitas}

Hasil uji validitas dan reliabilitas dapat dilihat dari nilai correlated item totaldan cronbach's aplha. Item pernyataan dapat dikatakan valid serta reliabel dan layak untuk digunakan dalam penelitian apabila nilai correlated item total $>0,30$ dan nilai cronbach's alpha $>0,7$. Dalam penelitian ini pernyataan dikatakan valid karena seluruh item pernyataan memiliki nilai coorelated item total $>0,3$ dan dinyatakan reliabel karena nilai cronbach's alpha $>0,7$. Berdasarkan hasil uji validitas dan reliabilitas, maka seluruh item pernyataan dikatakan layak untuk digunakan dalam penelitian.

\section{Karakteristik Responden}

Mayoritas responden dalam penelitian ini berjenis kelamin laki - laki dengan jumlah 125 orang (56,8\%), berusia 16-19 tahun tahun yaitu 216 orang (98,2\%) dan berada ditingkatan sekolah SMA/SMK/Sederajat dengan 218 orang $(99,1 \%)$.

\section{Hasil Uji ANOVA}

Untuk dapat menggunakan uji statistik ANOVA harus dipenuhi asumsi Homogeneity of Variance. Variabel dependen harus memiliki varian yang sama dalam setiap kategori variabel independen. Syarat tes homogeneity of variance adalah nilai signifikan $>0,05$ dan dalam melakukan uji homogeneity of variance ditemukan nilai levene test 0,261 . Jadi data yang diolah bersifat homogeny dan layak untuk dilakukan uji selanjutnya. Hasil pengujian ANOVA dapat dilihat pada tabel 2.

Tabel 2.

\section{Hasil Uji ANOVA}

\begin{tabular}{llllll}
\hline & $\begin{array}{l}\text { Sum of } \\
\text { Squares }\end{array}$ & df & $\begin{array}{l}\text { Mean } \\
\text { Square }\end{array}$ & F & Sig. \\
\hline Between & & & & & \\
Groups & 123,284 & 4 & 30,821 & 3,662 & 0,007 \\
Within Groups & 1809,711 & 215 & 8,417 & & \\
Total & 1932,995 & 219 & & & \\
\hline
\end{tabular}

Sumber: data primer (diolah peneliti)

Pada tabel 2, dapat dilihat bahwa nilai sig. sebesar 0,007 maka hipotesis pertama (H1) yang menjelaskan bahwa terdapat perbedaan rata-rata pengaruh yang diberikan oleh tiap-tiap brand ambassador diterima, karena jika nilai sig. >0,05 maka rata-rata pengaruh tiap brand ambassador terhadap keputusan pembelian konsumen dari Ruangguru itu sama. Namun apabila nilai sig. $<0,05$ maka rata-rata pengaruh yang diberikan oleh tiap brand ambassador terhadap keputusan pembelian konsumen Ruangguru itu berbeda.

Untuk melihat perbedaan yang terdapat pada Brand ambasador Ruangguru, dilakukan uji Multiple Comparisons. Hasil uji Multiple Comparisons, menunjukkan nilai sig. pada bagian profesi brand ambassador penyanyi dan atlet begitu juga sebaliknya menunjukkan angka 0,009. Dapat dijelaskan bahwa terdapat perbedaan hasil rata-rata karena nilai sig. dibawah 0,05 . Sedangkan selain dari profesi kedua brand ambassador tersebut tidak ada perbedaan hasil rata-rata.

\section{Hasil Uji Regresi}

Regresi digunakan untuk membuktikan hipotesis 2. Sebelum melakukan analisis regresi, terlebih dahulu dilakukan uji asumsi normalitas residual dan heteroskedatisitas. Uji normalitas dengan Kolmogorov-Smirnov, diperoleh hasil signifikan 0,29>0,05, sehingga memenuhi asumsi normalitas. Hasil uji heteroskedatisitas dan korelasi Rank Spearman antara residual dengan variabel bebas (brand ambassador), diperoleh hasil signifikan 0,348>0,05. Sehingga tidak terjadi heteroskedatisitas. Dengan begitu data dapat dikatakan berdistribusi normal dan telah memenuhi syarat digunakan untuk pada tahap selanjutnya. 
Iswanto \& Sanaji. Pengaruh Perbedaan Karakteristik Brand Ambasador terhadap Keputusan Pembelian Konsumen Ruangguru

Hasil pengujian hipotesis 2 ditunjukkan pada tabel 3.

Tabel 3.

HASIL UJI HIPOTESIS \& KELAYAKAN MODEL

\begin{tabular}{|c|c|c|c|}
\hline \multicolumn{4}{|c|}{ Uji Hipotesis } \\
\hline \multicolumn{4}{|c|}{ Unstandardized Coefficients } \\
\hline Model & $\mathrm{B}$ & Std. Error & Sig. \\
\hline (Constant) & 10,429 & 1,614 & 0,000 \\
\hline Brand ambassador & 0,152 & 0,027 & 0,000 \\
\hline \multicolumn{4}{|c|}{ Uji Kelayakan Model } \\
\hline $\mathrm{R}$ & R Square & Adjusted R Square & Std. Error of the Estimate \\
\hline 0,361 & 0,130 & 0,126 & 2,777 \\
\hline
\end{tabular}

Sumber: data primer (diolah peneliti)

Pada tabel 3, dengan melihat nilai B dan Sig. diketahui bahwa hipotesis kedua (H2) mengenai hubungan antara brand ambassador terhadap keputusan pembelian dapat dikatakan berpengaruh positif karena Sig. menunjukkan $0,000<0,05$. Berdasarkan hasil kelayakan model pada tabel 3 dapat dilihat pada nilai R Square menunjukkan angka 0,130. Dengan begitu model pada penelitian ini $13 \%$ faktor dipengaruhi oleh brand ambassador, sedangkan 87\% dipengaruhi oleh faktor lain.

\section{Perbedaan Pengaruh Brand ambassador Berdasarkan Profesi/Karakteristik}

Sesuai dengan hasil analisis, diperoleh hasil bahwa terdapat perbedaan rata-rata pengaruh yang disebabkan oleh brand ambassador. Artinya, bahwa perbedaan profesi/karakteristik pada brand ambassador Ruangguru ini memberikan pengaruh yang berbeda-beda pula terhadap keputusan pembelian konsumen. Hasil tersebut juga menunjukkan bahwa hipotesis pertama diterima yaitu, Terdapat perbedaan rata-rata pengaruh terhadap keputusan pembelian konsmen dari beberapa brand ambassador dari Ruangguru. Hal ini juga sesuai dengan teori yang dikemukakan oleh Apejoye (2013), bahwa setiap endorser memiliki power, dan jumlah power ini yang menentukan sejauh mana perilaku orang dipengaruhi. Di mana penggunaan brand ambassador pada Ruangguru ini menggunakan Multiple Brand ambassador dan setiap brand ambassador memiliki power masingmasing untuk sejauh mana akan memengaruhi keputusan orang lain.

Kok dan You (2013) menyatakan bahwa daya tarik sumber atau didefinisikan sebagai sifat yang menarik seperti fisik, kepribadian, dan keakraban, dimana daya tarik sumber ini hal yang memengaruhi komunikasi persuasif yang disampaikan kepada target audiens pastinya juga berbedabeda. Hal ini dikarenakan daya tarik sumber setiap brand ambassador pada Ruangguru juga beragam profesi/karakteristik. Hasil Multiple Comparisons menunjukkan bahwa perbedaan yang signifikan diperoleh dari brand ambassador yang berprofesi Penyanyi dan Atlet. Hal ini dikarenakan jumlah followers akun sosial media instagram yang memiliki selisih yang sangat signifikan juga dimana jumlah followers pada profesi Atlet hanya berjumlah 1,4 juta, sedangkan jumlah followers pada profesi Penyanyi berjumlah 7,7 juta. Namun, sebenarnya pada profesi Penyanyi ini tidak terdapat kesesuaian (kecocokan) dengan Ruangguru seperti yang dijelaskan oleh Lea-Greenwood, (2012:77) bahwa seorang brand ambassador itu haruslah memiliki kecocokan dengan merek dan mendukung merek tersebut berdasarkan profesi mereka. Dimana profesi Penyanyi ini seharusnya lebih cocok apabila menjadi seorang brand ambassador sebuah merek/produk yang berhubungan dengan musik, seperti; Eross Candra selaku gitaris dari band Sheila On 7 yang menjadi brand ambassador Fender yang merupakan sebuah perusahaan yang memproduksi gitar.

Penggunaan brand ambassador yang cocok untuk Ruangguru selaku penyedia layanan bimbingan belajar online yang berbasis pendidikan ini seharusnya memiliki seorang brand ambassador yang memiliki prestasi di bidang akademik yang telah memiiliki penghargaan dari kejuaraan nasional 
maupun internasional. Jumlah responden terbanyak juga ditemukan pada profesi penyanyi, hal tersebut juga yang menyebabkan mengapa nilai signifikan pada profesi penyanyi memiliki hasil signifikan yang paling besar. Jumlah brand ambassador Ruangguru pada profesi Penyanyi ini juga memiliki 3 orang di dalamnya yang berarti pada profesi Penyanyi merupakan jumlah terbesar di banding dengan yang lainnya, alasan tersebut juga yang menyebabkan kenapa jumlah responden lebih banyak pada profesi Penyanyi sehingga menyebabkan nilai signifikan yang tinggi pada profesi Penyanyi. Anneth Delliecia Nasution yang termasuk dalam brand ambassador dalam profesi Penyanyi ini mempunyai catatan sebagai juara FLS2N tingkat provinsi Kalimantan Timur pada tahun 2014 yang lalu, dimana prestasi akademik ini menjadikan contoh untuk para followers Anneth untuk menggunakan jasa dari Ruangguru.

\section{Pengaruh Brand ambassador terhadap Keputusan Pembelian}

Pengaruh brand ambassador terhadap keputusan pembelian terdapat pengaruh positif, artinya penggunaan brand ambassador ini memengaruhi keputusan pembelian konsumen pada Ruangguru. Hasil ini menunjukkan bahwa hipotesis kedua (H2) dapat diterima dan didukung dengan hasil penelitian Putra et.al. (2014) bahwa brand ambassador berpengaruh signifikan terhadap variabel keputusan pembelian. Kemudian Wang et al. (2016) juga menyatakan bahwa penggunaan brand ambassador atau celebrity endorsement akan membantu menciptakan hubungan emosional yang kuat antara merek dengan konsumen sehingga secara tidak langsung akan berdampak pada keputusan pembelian konsumen.

Hasil dalam uji regresi ini juga serupa dengan penelitian yang dilakukan oleh Prawira et al. (2012) bahwa penggunaan brand ambassador tidak sepenuhnya mempunyai hubungan terhadap keputusan pembelian, namun ada faktor lain yang memengaruhi. Samosir et al. (2016) juga menunjukkan bahwa pengaruh Dewi Sandra sebagai brand ambassador kosmetik Wardah terhadap keputusan pembelian adalah sebesar $18,4 \%$ sedangkan $81,6 \%$ sisanya dipengaruhi oleh variabel lain yang tidak diteliti. Penggunaan multiple brand ambassador pada Ruanguru ini sama sekali tidak terdapat profesi/karakteristik yang berhubungan lansung dengan bidang akademik, yang artinya tidak adanya kesesuaian antara profesi para brand ambassador dengan merek yang di dukung yang menyebabkan tidak maksimalnya pengaruh yang begitu besar terhadap keputusan pembelian konsumen.

\section{KESIMPULAN}

Berdasarkan hasil dari penelitian ini, maka kesimpulan dari penelitian ini adalah terdapat rata-rata perbedaan pengaruh dari penggunaan multiple celebrity endorsers pada Ruangguru terhadap keputusan pembelian. Perbedaan rata-rata pengaruh yang signifikan ditemukan pada profesi "Penyanyi" dan "Atlet". Penelitian ini juga menemukan bahwa terdapat pengaruh brand ambassador terhadap keputusan pembelian, namun hanya berpengaruh kecil dan sisanya dipengaruhi oleh faktor lain yang tidak diteliti

Penelitian ini tidak terlepas dari beberapa keterbatasan atau hambatan. Pengambilan data responden yang secara online melalui instagram dan whatsapp, tidak bisa menjadi patokan untuk dapat menyebar angket secara online dengan merata sesuai dengan usia pada kriteria 11 - >19 tahun. Hasil dari nilai multiple comparisons dapat dilihat bahwa peneliti hanya menemukan perbedaan rata-rata hanya pada 2 profesi/karakteristik brand ambassador saja yaitu, Atlet dan Penyanyi karena seharusnya dari 5 perbedaan klasifikasi berdasarkan profesi harusnya ditemukan hasil yang berbeda namun hanya 2 profesi saja yang terbukti signifikan berbeda. Penelitian selanjutnya, disarankan pengambilan data responden dilakukan secara langsung dan merata berdasarkan usia yang menjadi target penelitian, sehingga data yang diperoleh lebih beragam dan diharapkan dapat memberikan hasil penelitian yang lebih baik. Kemudian dalam hasil uji kelayakan model dalam penelitian ini ditemukan hasil bahwa pengaruh yang diberikan oleh variabel brand ambassador hanya sebesar $13 \%$ dan $87 \%$ lainnya dipengaruhi oleh faktor lain yang tidak di teliti, oleh karena itu disarankan untuk penelitian selanjutnya untuk meneliti faktor-faktor lain yang memengaruhi keputusan pembelian. 
Iswanto \& Sanaji. Pengaruh Perbedaan Karakteristik Brand Ambasador terhadap Keputusan Pembelian Konsumen Ruangguru

Berdasarkan fenomena yang terjadi akibat wabah Covid-19, sepanjang tahun 2020 diprediksi akan menjadikan teknologi informasi di Indonesia bahkan seluruh dunia terutama aplikasi bimbingan belajar berbasis online menjadi solusi untuk para pelajar yang tidak dapat melaksanakan kegiatan belajar di sekolah mejadi solusi untuk dapat belajar dirumah. Karena belajar merupakan kegiatan yang sangat penting untuk para pelajar, apalagi di masa pandemi Covid-19 ini menjadikan semua kegiatan yang melibatkan banyak orang tidak diperbolehkan karena dapat memperluas efek penularan. Diharapkan aplikasi bimbingan belajar berbasis online seperti Ruangguru ini dapat mengkampanyekan betapa pentingnya layanan belajar secara online ini agar kegiatan belajar mengajar disekolah dapat digantikan dengan belajar di rumah secara optimal berkat penggunaan jasa aplikasi bimbingan belajar berbasis online. Dengan demikian akan menjadikan keuntungan bagi Ruangguru akan dapat menarik konsumen dalam jumlah besar.

Terdapat implikasi teoritis yang dihasilkan dari penelitian ini. Penelitian ini mendukung teori bahwa perbedaan karakteristik setiap brand ambassador pada penggunaan multiple celebrity endorsers akan memberikan pengaruh yang berbeda-beda terhadap keputusan pembelian konsumen. Selain itu implikasi dari penelitian ini untuk perusahaan yang menawarkan jasa bimbingan belajar online bisa lebih fokus kepada calon konsumen yang sedang belajar di bangku SMA/SMK/Sederajat karena berdasarkan karakteristik responden pada penelitian ini di didominasi oleh para pelajar SMA/SMK/Sederajat karena memang tingkat kesulitan pada masa belajar saat itu dan jumlah mata pelajaran yang semakin banyak. Kemudian dalam pemilihan penggunaan seorang brand ambassador, sebuah merek atau perusahaan tidak hanya melihat besarnya popularitas dari seorang brand ambassador tersebut, namun sebaiknya perusahaan lebih memperhatikan profesi yang sesuai dengan bidangnya, sehingga seorang brand ambassador dapat mendukung merek dengan maksimal karena terdapat kesesuaian antara profesi dengan merek/perusahaan yang didukung dan diharapkan dapat meningkatkan pengaruh keputusan pembelian konsumen sama seperti yang Ruangguru lakukan dengan menggandeng Anneth menjadi salah satu brand ambassador, di lain sisi dia seorang penyanyi yang terkenal namun juga pernah mencatatkan prestasi di bidang akademik menjadi juara FLS2N pada tingkat provinsi Kalimantan Timur. Namun ada baiknya agar tujuan utama dari penggunaan brand ambassador itu sendiri melibatkan orang-orang dengan figur yang kuat dan tentunya profesinya memiliki kesesuaian dengan merek seperti misalnya Ruangguru menjadikan Maudy Ayunda sebagai brand ambassador dimana ia menyelesaikan studinya di Oxford University dengan nominasi salah satu lulusan terbaik.

\section{DAFTAR PUSTAKA}

Agnihotri A, et. al. (2018). Are Multiple Brand Endorsements Economically Effective?. Journal of Product \& Brand Management. , 27(5), 523-533

Apejoye A. (2013). Influence of Celebrity Endorsement of Advertisement on Students' Purchase Intention. Journal Mass Communication and Journalism. 3(3),3-10.

APJII. (2020). Laporan survei internet apjii 2019 - 2020 (Vol. 2020). Retrieved 7 January 2020, from https://apjii.or.id/survei

Bbc.com. (2018). Pelajar Indonesia jadi salah satu pengguna teknologi tertinggi di dunia. Retrieved January 7, 2020, from bbc.com website: https://www.bbc.com/indonesia/majalah46500293\#: :text=Pelajar Indonesia adalah yang tertinggi,54\%25)\%2C setelah Amerika Serikat.

B. Uno, H., \& Lamatenggo, N. (2017). Landasan Pendidikan. Jakarta: PT. Bumi Aksara.

Elis dan Tyas. (2013). Pengaruh harga dan citra merek terhadap keputusan pembelian televisi semarang. Jurnal Manajemen dan Bisnis. 19(1). 
Ghozali. (2013). Aplikasi Analisis Multivariate dengan Program IBM SPSS 23. Semarang: Badan Penerbit Universitas Diponegoro.

Goutam D. (2013). Influence of Brand ambassadors on Buying Behavior of Soft Drinks: With Reference to Belgaum City. Impact International Journal of Research. 1(4).

Hafilah N E, et. al. (2019). The Effect on Brand ambassador, Brand Image, Product Quality, and Price on Purchase Decisions Samsung Smartphones. SSRN.

Hariandja E, Wang F, Hariandja S. (2016). The Influence of Brand Ambassador on Brand Image and Consumer Purchasing Decision: A Case of Tous Les Jours in The Influence of Brand Ambassador on Brand Image and Consumer Purchasing Decision : local or international brands in the market market in Indon. International Conference Od Enterpreneurship, (March), 292306.

Ikhsan M, et. al. (2014). Pengaruh Brand ambassador terhadap Brand Image Serta Dampaknya Terhadap Keputusan Pembelian. Jurnal Administrasi Bisnis (JAB). 12(1).

Kanuk dan Schiffman. (2008). Perilaku Konsumen. Edisi 7, Jakarta: Indeks

Katadata.co.id. (2020). 7 Aplikasi Belajar Online Gratis untuk Siswa dan Guru. Retrieved January 7, 2020, from katadata.co.id website: https://katadata.co.id/marthathertina/berita/5e9a4214242f1/7-aplikasi-belajar-online-gratisuntuk-siswa-dan-guru.

Karina Priskila E, Sembiring Carolina C, Silvanita Mangani. (2016). Analisis Keputusan Pembelian di Tokopedia yang dipengaruhi Celebrity Endorser, Brand Image, Kelompok Referensi dan Usia. Special Issues of Marketing Mangement, 1(1), 2.

Kok Wei K. dan You Li. (2013). Measuring the Impact of Celebrity Endorsement on Consumer Behavioural Intentions: A Study of Malaysian Consumers. International Journal of Sports Marketing and Sponsorship.14(3), 2-22.

Kotler, Philip dan Keller. (2007). Manajemen Pemasaran. Jilid 1, Edisi Kedua belas, PT Indeks, Jakarta.

Kotler, Philip and Keller, Kevin, L. (2016). Manajemen Pemasaran, Edisi kelima belas, Jakarta: Erlangga

Kotler, Philip dan Amstrong, Gary. (2014). Prinsip - Prinsip Pemasaran. Jilid 1. Jakarta: Airlangga.

Kompasiana.com (2020). Mampukah Bimbel Online jadi Primadona? Retrieved January 7, 2020, from kompasiana.com website: https://www.kompasiana.com/muhammadtharieqwaldopo3478/5baf3727ab12ae36a7057b72/m ampukah-bimbel-online-menjadi-primadona.

Kurniawan, K. (2017). Pengaruh Intensitas Bermain Game Online Terhadap Perilaku Proskatinasi Akademik Pada Mahasiswa Bimbingan dan Konseling Universitas PGRI Yogyakarta. Jurnal Konseling GUSIJANG Vol. 3 No. 1. Universitas PGRI Yogyakarta.

Lea-Greenwood. (2012). Fashion Marketing Communications. Edisi 1, USA: Wiley

Lunardo, R., \& Roux, D. (2015). In-Store Arousal and Consumers' Inferences of Manipulative Intent in the Store Environment European Journal of Marketing environment Article information: (May). https://doi.org/10.1108/EJM-10-2013-0560 
Iswanto \& Sanaji. Pengaruh Perbedaan Karakteristik Brand Ambasador terhadap Keputusan Pembelian Konsumen Ruangguru

Maharani K, Totoatmojo. (2015). The Celebrity Endorser Effect Toward Purchase Intention On Instagram Social Media. Sustainable Development of Asian Commnity. (3).

Mangkosa, R., Mohube, K. (2007). Peer Influence on Young Adult' Product Purchase Decisions. African Journal of Business Management. 2.

Naresh, Maholtra. (2009). Riset Pemasaran. Jilid dua, edisi keempat, Jakarta: Indeks

Paticia P C, Shihab M, Kamil I. (2014). The Influence of Using Snowee Instagram Account as the Brand Ambassador towards the Brand Awareness of Nestlé Purina PRO PLAN. Communication Studies - School of Humanities, 1-24.

Prakoso H, Iriani S, et. al. (2015). Pengaruh Kualitas Produk dan Kelompok Acuan Terhadap Keputusan Pembelian Sepeda Motor Suzuki Satria F150. Journal of Research in Economics And Management. 15(2).

Prawira R Y, et. al. (2012). Hubungan Karakteristik Brand ambassador Honda Spacy Helm-Ini dengan Tahapan Keputusan Pembelian Konsumen. eJournal Mahasiswa Universitas Padjadjaran. 1(1).

Putra, M. I., Suharyono, \& Abdillah, Y. (2014). Pengaruh Brand Ambassador Terhadap Brand Image Serta Dampaknya Terhadap Keputusan Pembelian ( Survey pada pengguna LINE di Asia). Jurnal Administrasi Bisnis (JAB) 12(1), 1-10.

Rehmet J, dan Dinnie K. (2013). Citizen brand ambassadors: Motivations and perceived effects. Journal of Destination Marketing \& Management. 2(1).

Rice D. H. et. al. (2012). Multiple Endorsers and Multiple Endorsements: The Influence of Message Repetition, Source Congruence and Involvement on Brand Attitudes. Journal of Consumer Psychology. 249-259.

Royan, Fransiscus, (2005). Marketing Celebrities, Jakarta: Erlangga,.

Sagia A, Situmorang S H. (2018). Pengaruh Brand ambassador, Brand Personality Dan Korean Wave Terhadap Keputusan Pembelian Produk Nature Republic Aloe Vera. Jurnal Manajemen Bisnis Indonesia. 5(2).

Samosir L, et. al. (2016). Effects of The Use Dewi Sandra as Wardah Brand ambassador on The Decision to Purchase Wardah Cosmetics in Bandung. Jurnal Sosioteknologi Universitas Telkom. 15(2).

Shimp. (2014). Komunikasi Pemasaran Terpadu. Edisi 8, Jakarta: Salemba Empat

Soesatyo, N dan Rumambi L. (2013). Analisa Credibility Endorser Model : Sikap Audience Terhadap Iklan dan Merek Serta Pengaruhnya Pada Minat Beli "Top Coffee". Jurnal Manajemen Pemasaran. 1(2).

Sugiyono. (2013). Metode Penelitian Pendidikan Pendekatan Kuantitatif Kualitatif dan $R \& D$. Bandung: Alfabeta

Sumarwan, U. (2014). Perilaku Konsumen. Jakarta: PT. Ghaila Indonesia

We Are Social. (2020). Riset: Ada 175,2 Juta Pengguna Internet di Indonesia. Retrieved January 7, 2020, from detik.com website: https://inet.detik.com/cyberlife/d-4907674/riset-ada-1752-jutapengguna-internet-di-indonesia. 
Yusiana, R., \& Maulida, R. (2015). Pengaruh Gita Gutawa Sebagai Brand Ambassador Pond ' S dalam mempengaruhi Keputusan Pembelian ( Studi Kasus Pada Mahasiswi Universitas Telkom Jurusan D3. Jurnal Ecodemica III(1), 311-316. 